\title{
Comprehensive Automation of Microprocessor Protection Relay Terminals Operated on AC Railways
}

\author{
Vostrikov Maksim Viktorovich', Daneev Aleksey Vasilyevich ${ }^{2}$, \\ Menaker Konstantin Vladimirovich', Sizykh Viktor Nikolaevich ${ }^{2}$ \\ ${ }^{1}$ Zabaikalsk Rail Transport Institute, A Branch of Irkutsk State Transport University, Chita, Russia \\ ${ }^{2}$ Irkutsk State Transport University, Irkutsk, Russia \\ Email: apirin1979@mail.ru, daneev@mail.ru, menkot@mail.ru,sizykh_vn@mail.ru
}

How to cite this paper: Viktorovich, V.M., Vasilyevich, D.A., Vladimirovich, M.K. and Nikolaevich, S.V. (2022) Comprehensive Automation of Microprocessor Protection Relay Terminals Operated on AC Railways. Journal of Applied Mathematics and Physics, 10, 491-503.

https://doi.org/10.4236/jamp.2022.102037

Received: December 19, 2021

Accepted: February 21, 2022

Published: February 24, 2022

Copyright $\odot 2022$ by author(s) and Scientific Research Publishing Inc. This work is licensed under the Creative Commons Attribution International License (CC BY 4.0).

http://creativecommons.org/licenses/by/4.0/

(c) (i) Open Access

\begin{abstract}
The article discusses the possibility of a potential reduction in the number of operations of microprocessor relay protection of feeders of the contact network of AC railways TsZA-27.5-FKS (FTS) for unknown reasons. Real statistics on the number of microprocessor relay protection operations at the $\mathrm{Bu}$ ryatskaya traction substation are presented, simulation of the real train situation (in accordance with the regime maps of the throughput capacity of the sections of the Trans-Baikal railway) was carried out in the specialized software complex "KORTES". Based on the results of the analysis of simulation modeling, the process of forming a unified template of settings using neural network technologies is considered, which characterizes only this specific regular train situation. To protect objects in the event of pre-emergency and emergency modes of operation of the traction power supply system, a variant of changing the standard operation algorithm of the TsZA-27.5-FKS (FTS) terminal by introducing additional blocks for calculating the predictive functions of current and voltage has been proposed.
\end{abstract}

\section{Keywords}

Automated System, Microprocessor, Relay Protection Devices, Feeder, Traction Substation

\section{Introduction}

At present, the traction substations of the Zabaikalskaya Railway use microprocessor-based relay protections (MRP) for overhead feeders of the AZ (m), TsZA27.5-FKS (FTS), InTer-27.5 brands [1] [2] [3]. Let us dwell on the TsZA-27.5- 
FKS (FTS) terminals in more detail, since the team of authors has previously considered the possibilities of automation and integration with the main MRP terminal of additional visualization systems and elements of "learnability" [4] [5].

The use of modern MRP systems leads to the implementation of new promising and potential opportunities:

- Design and new approaches to the principles of building the defenses themselves;

- Guaranteed operation of the MRP even in the absence of some of the necessary information;

- Pre-forecast of the occurrence of pre-emergency situations (according to some parameters);

- Fundamental self-diagnostics and introspection of the operation of the MRP modules;

- Work of MRP on more accurate digital parameters;

- Receiving, analyzing and storing data arrays received from neighboring linear objects of the traction power supply system;

- Automatic generation of MRP settings according to operating parameters and the possibility of their manual adjustment.

At the same time, it is impossible not to note the structural shortcomings of modern MRP and the problems arising during its operation:

- Uninterrupted operation and quality of functioning (strict adherence to the temperature regime);

- Violation of the conditions of electromagnetic compatibility and noise immunity, especially in cases of the possibility of using super-powerful directed electromagnetic influences;

- Overly complex and multi-level functionality of setting operating parameters both when using the functionality of the control unit and when using the appropriate automated control system (software);

- The initially high cost of the finished MRP terminal (including delivery, installation and commissioning);

- Excessive sensitivity, leading to the operation of the MRP for unknown reasons;

- The overall reliability of the MRP, as a result, turns out to be practically the same as in the case of the operation of relay protections of previous generations (electromechanical, electronic).

Analyzing the statistics of the operation of the MRP (for example, the $\mathrm{Bu}$ ryatskaya traction substation (TS)) for 2021, one can make sure that not the last place in the total number of outages is occupied by outages for unknown reasons (Figure 1).

Studying this issue, associated with a possible decrease in the number of outages of the MRP for unknown reasons, the authors propose to consider the real process of organizing train traffic on a specific section of the Trans-Baikal Railway, using the KORTES software complex generally accepted for these purposes 


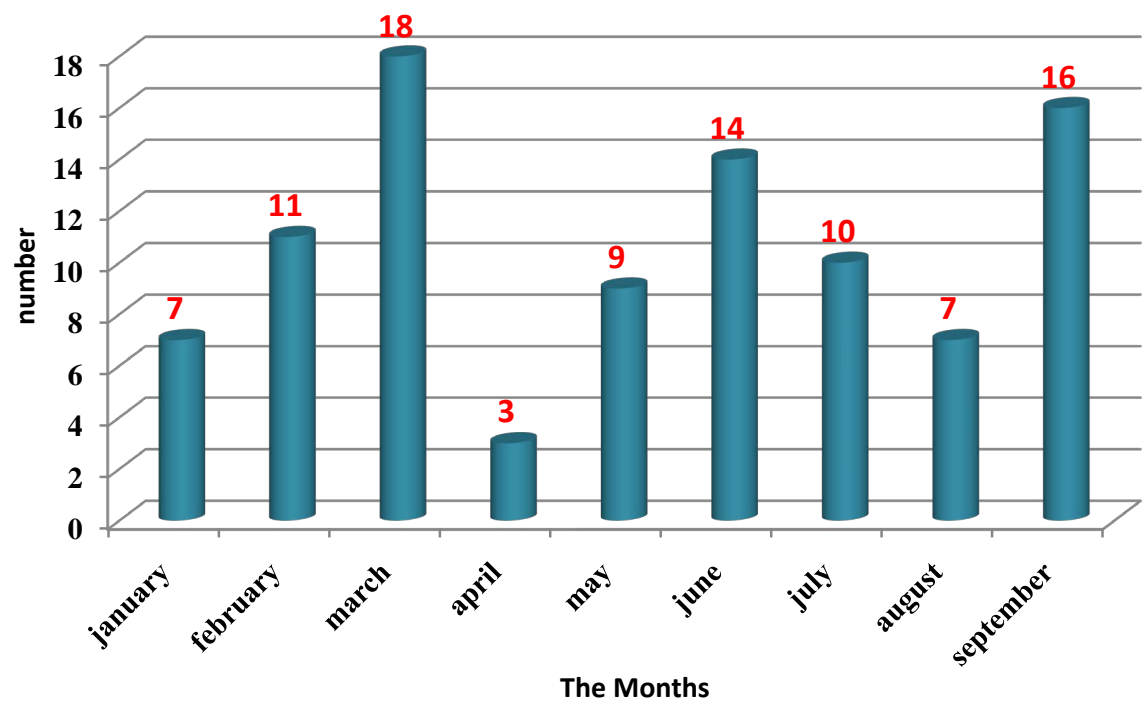

Figure 1. Distribution of the number of outages due to unknown reasons (for the period January-September 2021) devices MRP TsZA-27.5-FKS (FTS) TS Buryatskaya.

on the Russian railway network (Complex calculations of traction power supply) [6]. In parallel with this, the processes associated with the possible comprehensive automation of the existing system of microprocessor-based protection of feeders of the contact network of traction substations of alternating current railways TsZA-27.5-FKS (FTS) will be considered. Based on the results of the study, options and recommendations for the modernization of existing and operating MRP terminals of the specified type will be proposed.

\section{Materials and Methods}

The object of research is a typical protection and automation unit (PAU) of a digital protection and automation device for a $27.5 \mathrm{kV}$ traction network feeder of AC railways (TsZA-27.5-FKS (FTS)).

The subject of the research is the standard algorithm for the operation of a digital protection and automation device for a $27.5 \mathrm{kV}$ feeder contact network (FCN) (TsZA-27.5-FKS (FTS)), the improvement of which is proposed by introducing additional blocks for calculating the predicted values of voltage, as well as a neural network for the formation of unified templates that characterize each specific train situation.

The study was carried out using the methods of statistical information processing, simulation of the operating modes of the traction power supply system of the railway section, neural network technologies and predictive evaluation of functions.

\section{Setting up the Experiment}

The section of the Karymskaya-Buryatskaya-Bulak railway was chosen as an experimental one; the studies were carried out at the Buryatskaya traction substation (TS). Calculations will be made in a specialized software package (SP) 
"KORTES" approved for use on the railway network of Russia and the countries of the Commonwealth of Independent States (CIS) for drawing up regime maps, carrying out traction calculations and calculating the throughput of sections [7] [8]. The general window for controlling modules and the functionality of the SP KORTES is presented below (Figure 2).

The result of the first stage of simulation modeling is the traction calculation for a single freight train weighing 6000 tons, driven by the Ermak-2ES5K electric locomotive when moving along the investigated section in an odd direction (Figure 3).

The second stage of the study is the formation of a power supply scheme for the traction power supply system (PSS) of the Karymskaya-Buryatskaya-Bulak section (Figure 4), the creation of a schedule for the movement of trains (circulating on this section) and the calculation of the available throughput to determine the main design parameters of the normal operation of the MRP FCN on TS Buryatskaya. The result of simulation moderation will be the following parameters that characterize the mode of operation of the section's STE and MRZ TsZA-27.5-FKS (FTS):

- Voltage levels on the buses of traction substations and on the current collector of the electric locomotive;

- Consumption of active and reactive electricity for traction of trains;

- Losses of electricity in the contact network and in the traction transformers of substations;

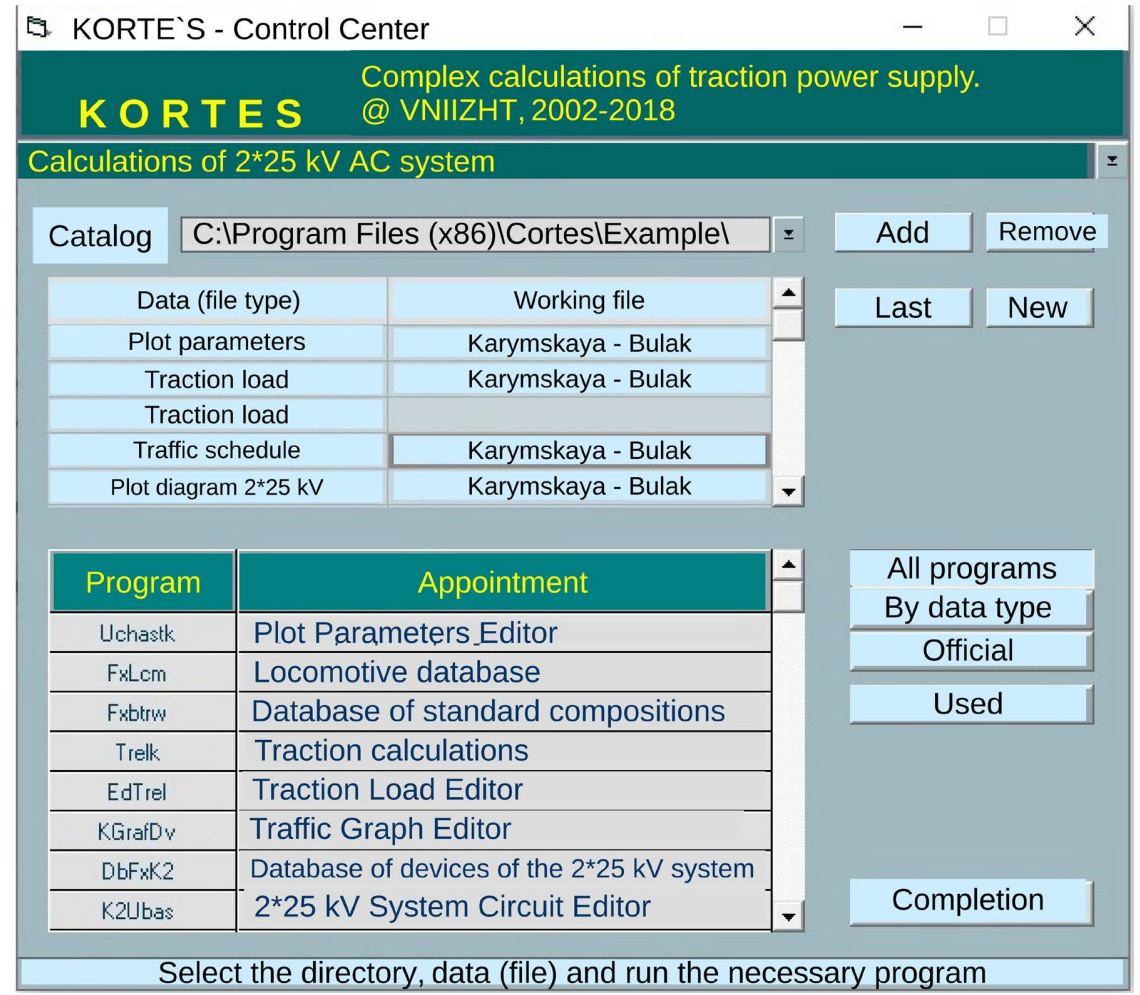

Figure 2. The main information window of the SP "KORTES" and the functionality of the modules included in it. 


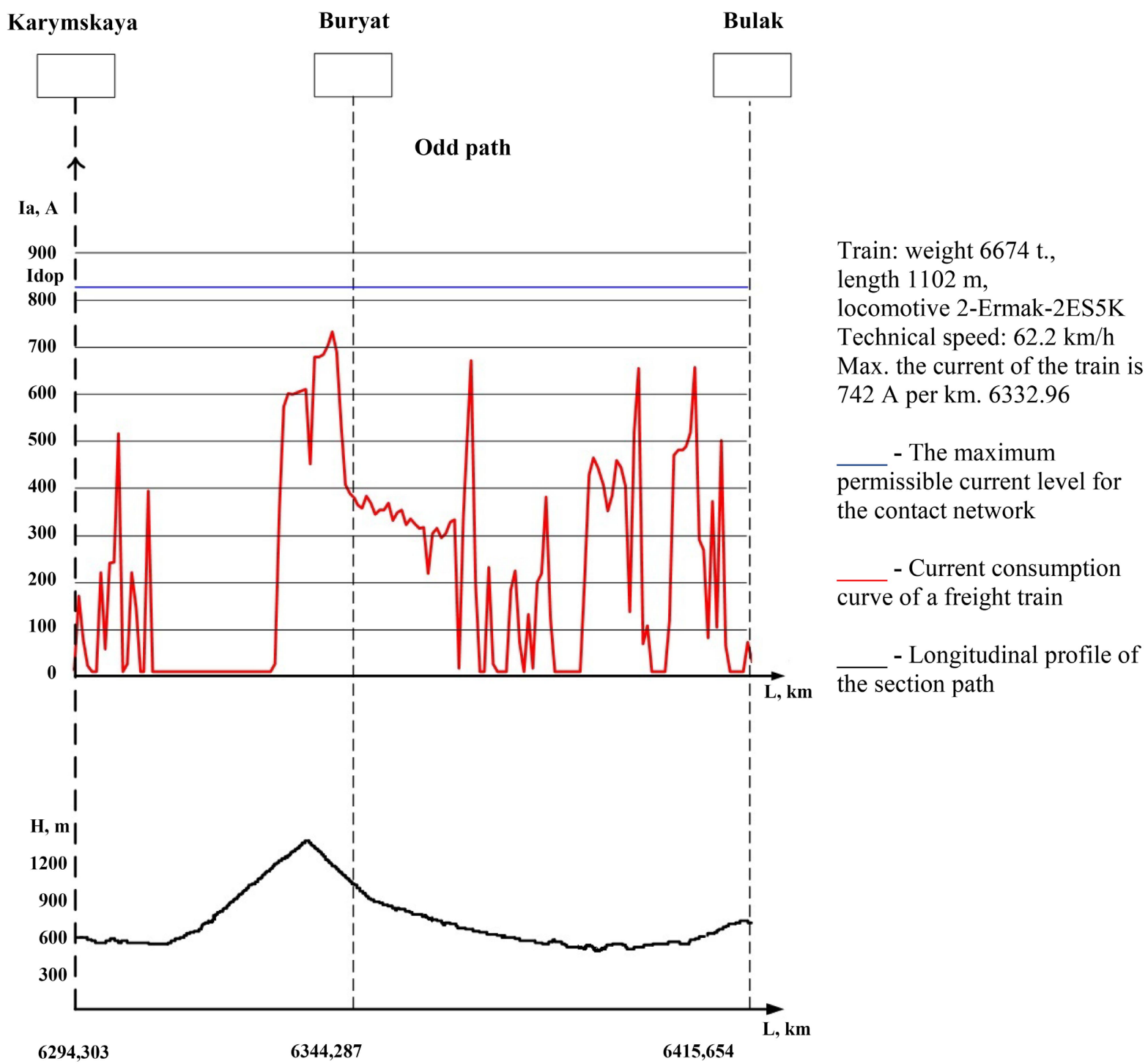

Figure 3. Results of traction calculation for a freight train with an electric locomotive of the Ermak series when moving along the Karymskaya-Buryatskaya-Bulak section (direction of movement-odd).

- Heating temperatures of wires of FCN substations of the site;

- Heating temperatures of windings and oil in traction transformers of substations;

- Parameters limiting the bandwidth, etc. (Figure 5).

The data obtained in this way: the type of electric locomotive, the mass of the train, its speed, the coordinate of being on the track profile at a given time, the voltage level in the contact network and the level of current flowing in it are the fundamental parameters (initial data) for the formation of a unified template for the settings of the MRP Central Locomotive-27.5-FKS (FCS) for a given, specific train situation.

Previously, the authors have already suggested using the data received by the duty personnel of traction substations via a dedicated wired channel from the automated system for maintaining and analyzing the schedule of the executed 


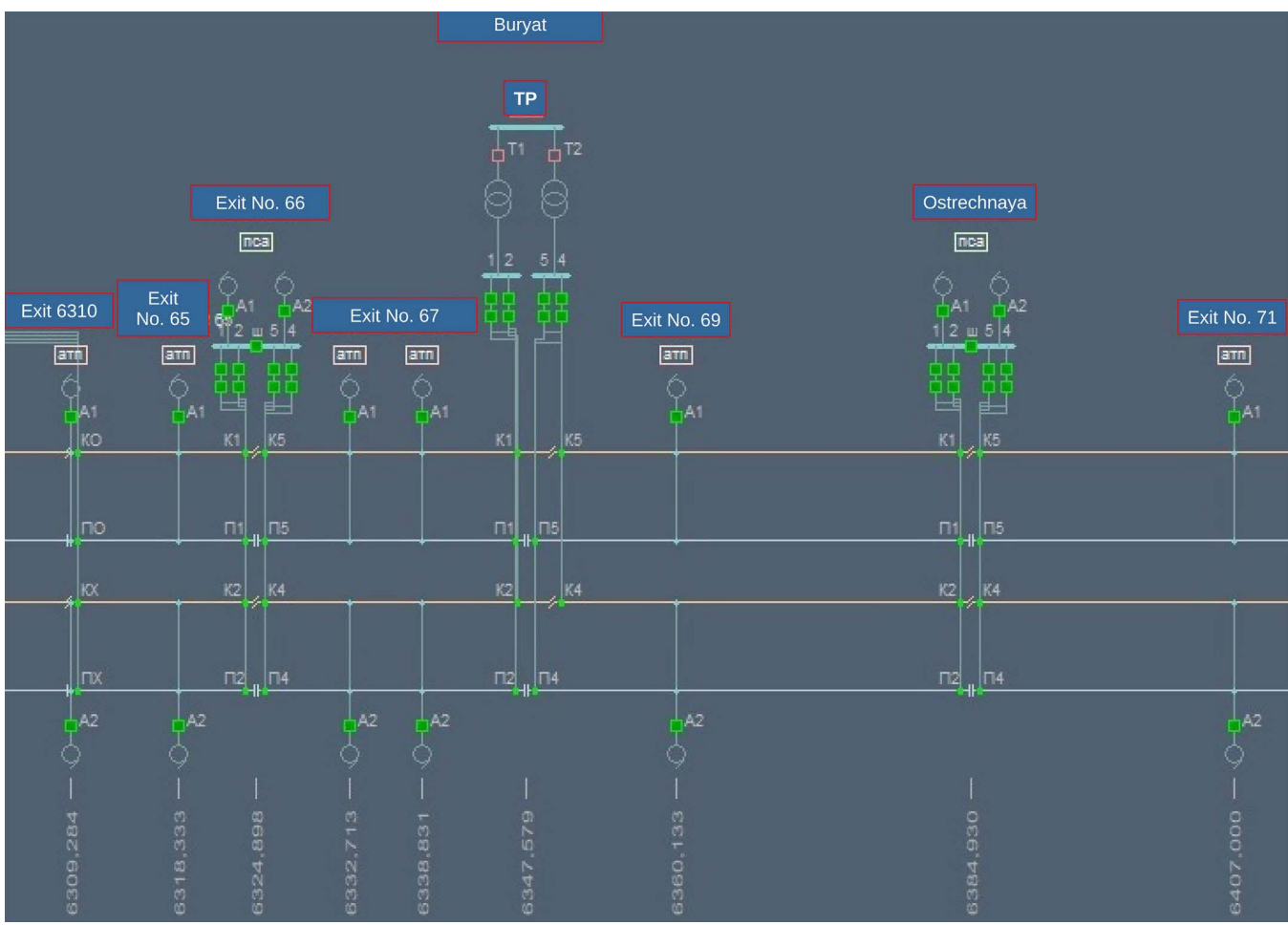

Figure 4. Power circuit of the traction power supply system of the site Karymskaya-Buryatskaya-Bulak, created in SP “KORTES”.

The main characteristics of the working mode of the site KARYMSKAYA - BULAK Calculation time, min: start 0; duration 1440; step 1.0;

Air temperature, ${ }^{\circ} \mathrm{C} 40$;

The graphs of the movement of the tracks 1 are used,

Power consumption: active, $\mathrm{kWh}-1720986$; reactive, kvar * h -969364.

losses in the traction network $26914(1.6 \%)$;

Transformer temperature, ${ }^{\circ} \mathrm{C} 74$ (additional $95^{\circ}$ oil) BURYAT (left shoulder);

Voltage: minimum 21,90 2-way zone BULAK - BURYAT

\begin{tabular}{|l|c|c|c|c|c|}
\hline \multicolumn{6}{|c|}{ Transformer loads of traction substations (Wa - active, Wr - reactive) } \\
\hline Namedsubstations & $\begin{array}{c}\mathrm{Wa}, \\
\mathrm{kWh}\end{array}$ & $\begin{array}{c}\mathrm{Wr}, \\
\mathrm{kVAr} * \\
\mathrm{~h}\end{array}$ & $\begin{array}{c}\text { Uk.wed, } \\
\mathrm{kV}\end{array}$ & $\begin{array}{c}\text { Windingtemperature. } \\
{ }^{\circ} \mathrm{C}\end{array}$ & $\begin{array}{c}\text { Oil } \\
\text { temperature. } \\
{ }^{\circ} \mathrm{C}\end{array}$ \\
\hline KARYMSKAYA & 299394 & -185182 & 27,50 & 69 & 65 \\
\hline BURYAT & 169039 & -163341 & 27,86 & 67 & 65 \\
\hline BULAK & 298898 & -109784 & 27,63 & 70 & 66 \\
\hline
\end{tabular}

\begin{tabular}{|c|c|c|}
\hline \multicolumn{3}{|c|}{ Minimum voltages on current collectors of locomotives } \\
\hline Substationzone & Way & Ue, $\mathrm{kV}$ \\
\hline \multirow{2}{*}{ KARYMSKAYA - BURYATSKAYA } & 1 & 21,06 \\
\cline { 2 - 3 } & 2 & 21,60 \\
\hline \multirow{2}{*}{ BURYATSKAYA - BULAK } & 1 & 22,07 \\
\cline { 2 - 3 } & 2 & 22,05 \\
\hline
\end{tabular}

\begin{tabular}{|l|c|c|c|}
\hline \multicolumn{4}{|c|}{ Electricity consumption and losses } \\
\hline Substations & $\begin{array}{c}\text { Full, } \\
\mathrm{kV} * \mathrm{~A} \cdot \mathrm{h}\end{array}$ & $\begin{array}{c}\text { Load losses in } \\
\text { transformers, } \\
\mathrm{kWh}\end{array}$ & $\begin{array}{c}\text { No-load losses in } \\
\text { transformers, } \\
\mathrm{kWh}\end{array}$ \\
\hline KARYMSKAYA & 352036 & 806 & 1440 \\
\hline BURYAT & 433946 & 865 & 2496 \\
\hline BULAK & 525424 & 1503 & 1224 \\
\hline
\end{tabular}

Figure 5. The main results of simulation in the SP "KORTES" operating modes of the traction power supply system of the Karymskaya-Buryatskaya-Bulak section when organizing train traffic using regime cards of throughput. 
movement of the Ural-VNIIZhT GUI [9], which also contains all the information necessary to form the template. However, in case of temporary physical absence of this wired channel (breakage, repair work, etc.), as an alternative, you can use simulation in the KORTES software package.

Consider the process of forming a unified template with settings for MRP TsZA-27.5-FKS (FCS) at the moment of the current train situation described above, based on the use of neural network technologies. The neural network (NN) topology for a given train situation is shown in Figure 6.

The description of the developed neural network in terms of linear algebra is carried out on the basis of binary matrices (for each layer, taking into account the bit depth), which are easy to use and most suitable for digital processing [10]. In order to identify the corresponding train situation during the training and/or regular operation of the $\mathrm{NN}$, it would be advisable to use the proven SHA-2 (SHA-256) hashing algorithm that has proven itself in solving many problems [11].

For a specific train situation, displayed in blue on the created NN, the final settings hash code (unified template) for automated monitoring and control of operating modes of the MRP TsZA-27.5-FKS (FTS) will have the following form (the neural network operation process is discussed in more detail in [12]):

$$
\begin{gathered}
\text { digest }=30 \text { ecc75187a469f76de14dc11f40af2cd5 } \\
\mathrm{d} 254 \mathrm{bb} 68 \mathrm{c} 0 \mathrm{xWEBx} 7647 \times 1636262307
\end{gathered}
$$

Such patterns fit well and characterize the normal operation modes of the PSS section when organizing train traffic in strict accordance with the regime maps.

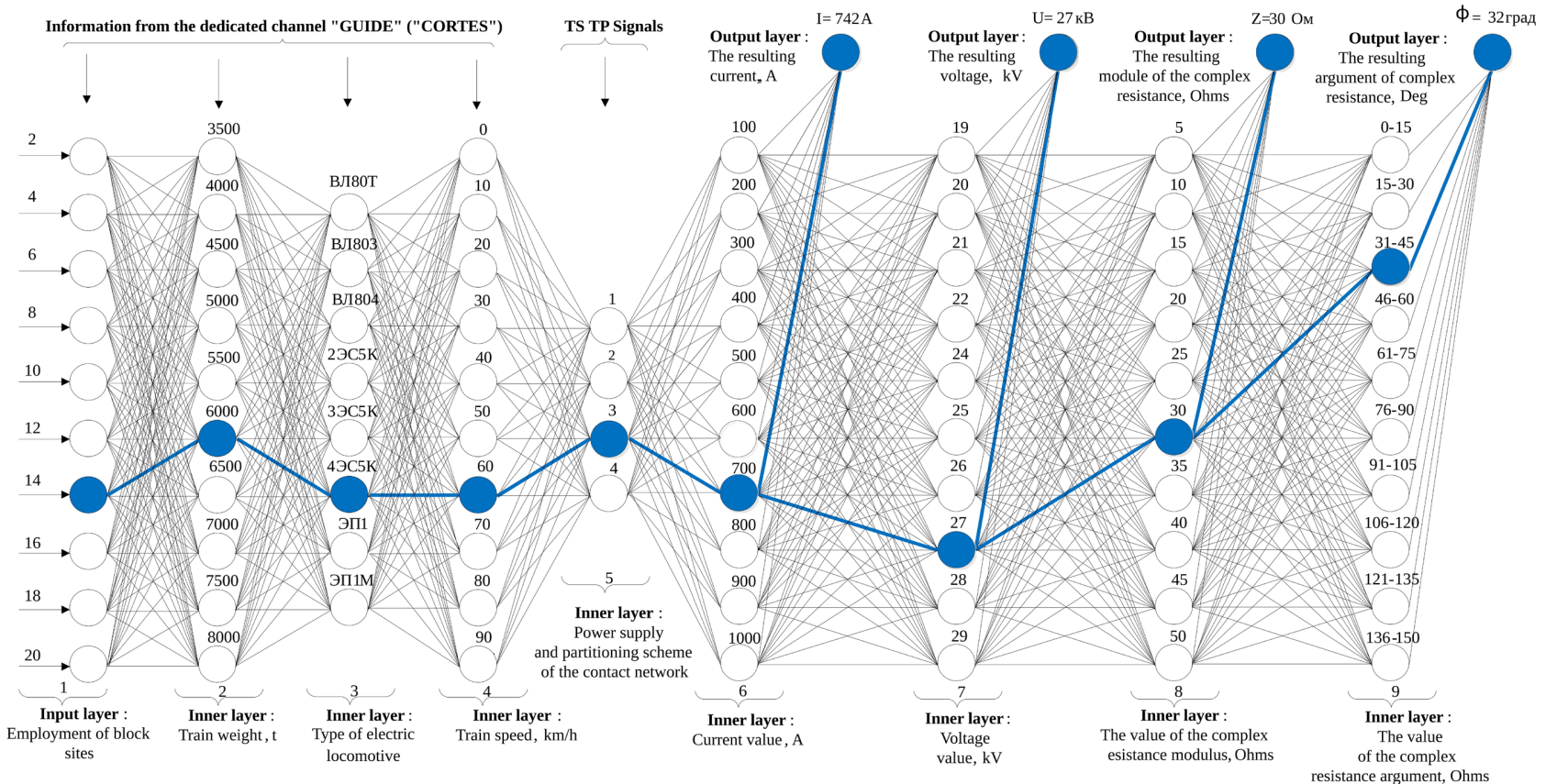

Figure 6. Topological diagram of a neural network for the formation of a unified template of settings for the MRP TsZA-27.5-FKS (FTS) on the example of a specific train situation on the Karymskaya-Buryatskaya-Bulak section when organizing train traffic using regime cards of capacity. 
Thus, for each current (unique) train situation, its own, unified template of settings will be determined, the base of which will be constantly replenished and stored on a separate personal computer (PC) by the traction substation duty personnel.

However, with a sudden change in the power supply circuit and sectioning of the contact network of the section, when using recuperation modes, changing the number and weight of trains, the occurrence of starting, transient currents and short-circuit currents, etc. for detuning from operation for unknown reasons, MRP TsZA-27.5-FKS (FTS), the authors propose to make some changes to the existing typical algorithm of the terminal [2], adding an additional branch to it (integrated between the second and third stages, but with the possibility of removing primary information directly from the automated inputs of the MRP terminal [12]), containing a block for galvanic isolation and preliminary scaling of input current and voltage signals (consisting of measuring current 1 and voltage transformers 2, blocks for setting control reference signals for current 3 and voltage 4 based on circuits PLL, blocks of digital frequency filters (Fourier filters) of the fundamental current 5 and voltage 6, blocks of registers of discrete values of current 7 and voltage 8); a unit for determining the current and predicted electrical parameters of the monitored current and voltage signals (consisting of modules 9 - 14 for calculating the angular frequency, the initial phase and the first derivative of the predictive functions of current and voltage), the accuracy and reliability of which are evaluated in [13]; a block for determining the amplitude values of the predicted current and voltage signals (consisting of modules 17 - 20 for calculating the amplitudes of the predicted current and voltage functions either by the values of the first derivatives of the corresponding monitored signals (found in the vicinity of zero marks), or by three experimental signal points (taken near local maxima), depending on the current phase (the choice of the option for calculating the values of the amplitudes of the predictive functions of current and voltage is carried out by comparison modules 15 and 16)); block for making a decision for emergency shutdown of the protected object (consisting of modules for comparing the values of the amplitudes of the predictive current and voltage functions with the values of the settings (22, 23, 28 and 30), time delay modules 24 and 31, modules of the registers of the values of the amplitudes of the predictive current functions (25) and voltage (32) for three predicted half-periods, modules for comparing the values of the amplitudes of the predictive functions of current (26) and voltage (33) with the setting values for two predicted half-periods). The final signal to disconnect the protected object is generated in block 36, depending on the operation algorithm of all previous blocks and modules (Figure 7).

The proposed branch can be automatically enabled/disabled using a software key, which is installed in a certain place of the standard operation algorithm of the MRP TsZA-27.5-FKS (FTS). At the same time, if the additional branch proposed by the authors is connected to the work of the standard algorithm, it works with it in parallel, without disrupting the main sequence of operations, 


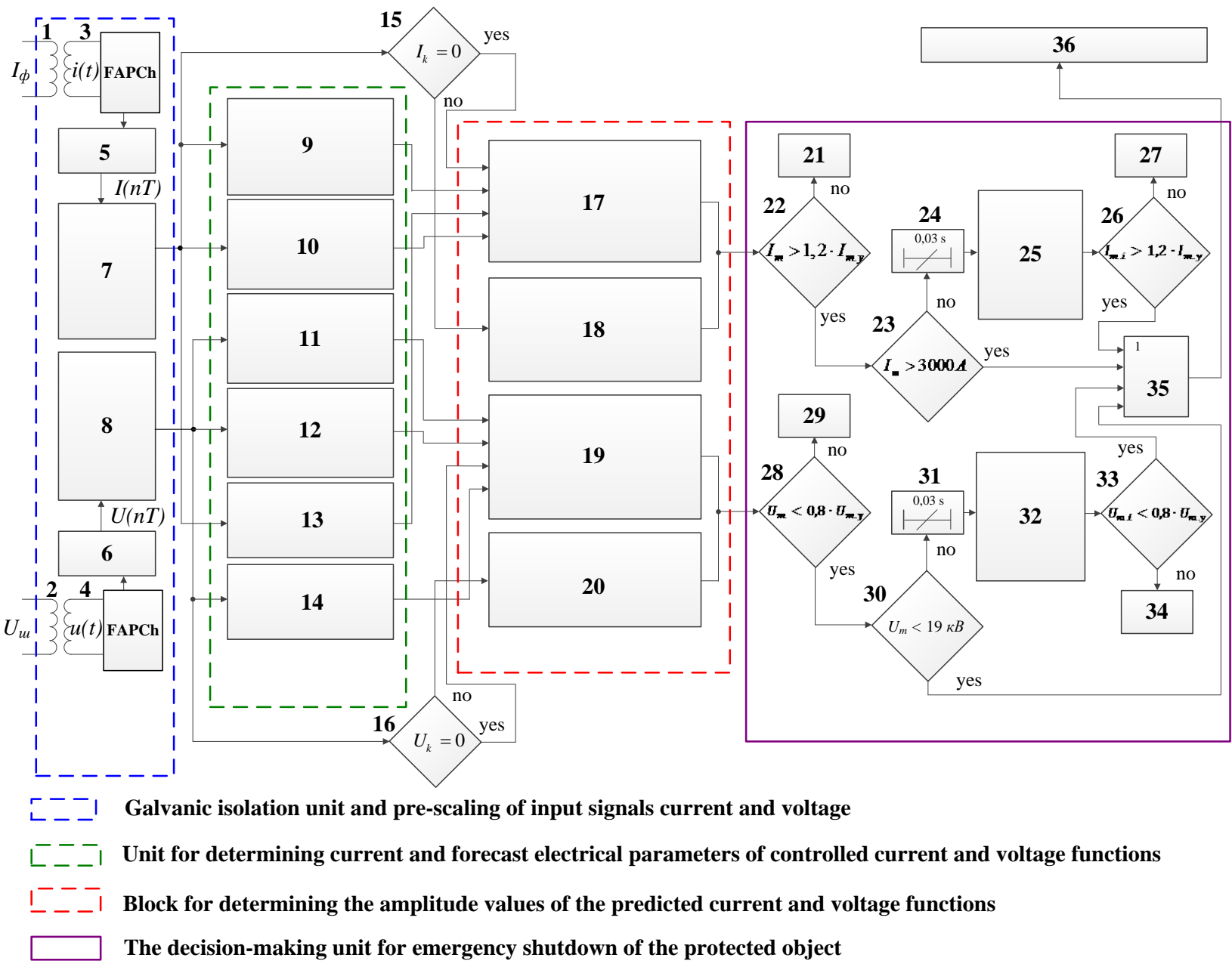

Figure 7. Block diagram of an additional branch proposed for integration into the standard MRP TsZA-27.5-FKS (FTS) algorithm.

but performing a "tracking" function (collection, analysis and processing of parameters of controlled functions and assessment of further possible changes using the predictive method). The result of the work will be the output to the personal computer of the duty personnel of color indication (block 36, Figure 7), according to which (including) further analysis of the emergency shutdown of relay protection will take place.

However, this technical solution can be implemented only after obtaining official consent to a partial change in the standard operation algorithm of standard MRP terminals by the manufacturer NIIEFA-ENERGO LLC with the involvement of their specialized personnel.

\section{Results of the Experiment}

The result of the experiment is the developed methodology and structural diagram of the proposed modernized MRP TsZA-27.5-FKS (FTS), which includes two independent, complementary "circuits": one of which contains automated systems tied to the PC of the duty personnel of the traction substation (system 
on-line visualization, processing and storage (in the form of splines) of oscillograms of voltages and currents flowing in the contact network [4] [14]; dedicated wired channel-the Ural-VNIIZhT GUID system [9]; SP KORTES [6]; neural network for the formation, storage and comparison of the base of unified setting templates corresponding to specific train situations under normal operating modes of the traction power supply system; color indication system of emergency operation under the standard standard algorithm (in comparison with the predictive method for estimating parameters proposed by the authors) for subsequent adjustment settings in order to reduce the number of trips for unknown reasons, and the second is an additional branch with elements of predictive

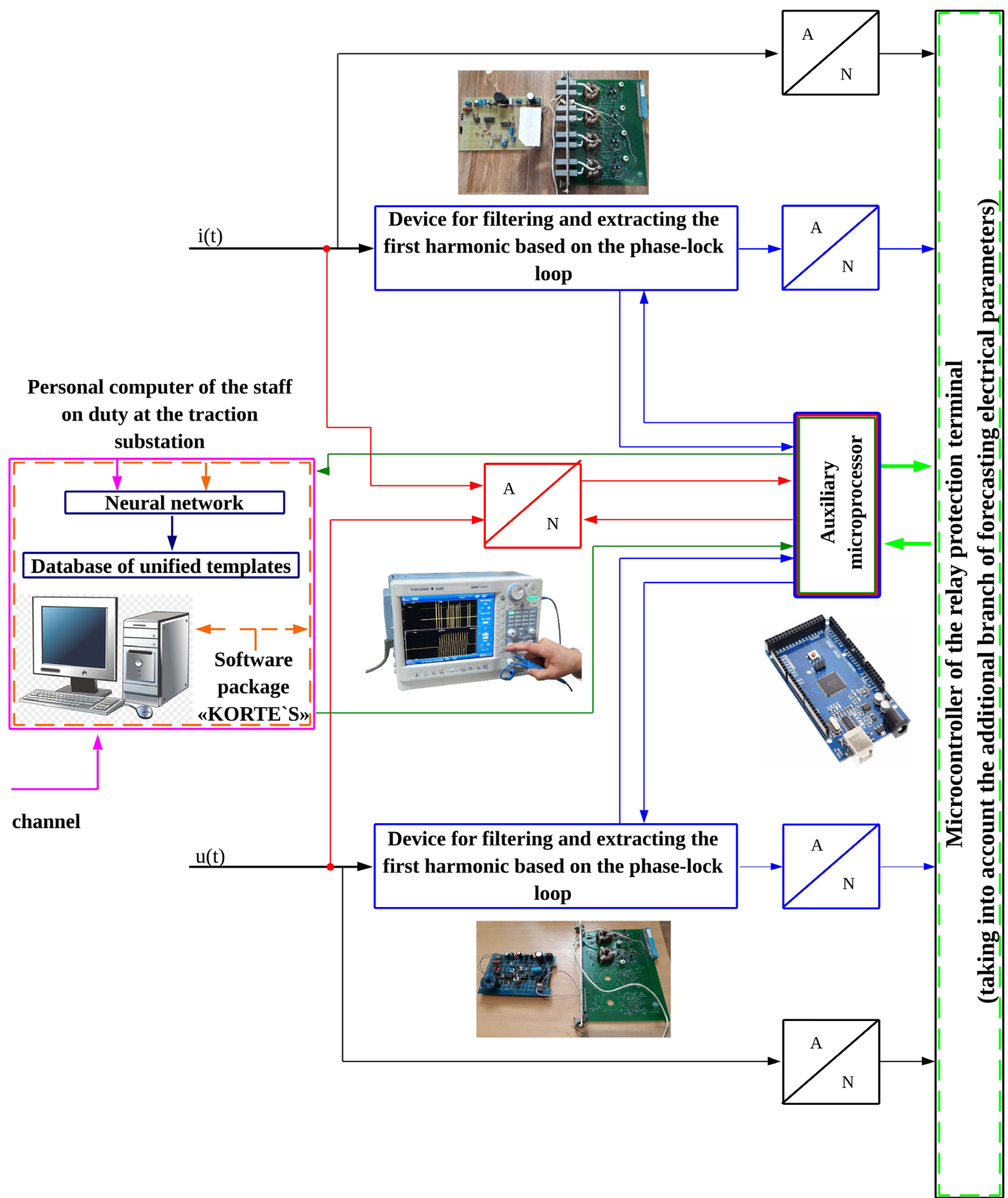

Figure 8. Schematic diagram of the integration and joint operation of the proposed automated systems, neural networks and software as part of a typical relay protection terminal TsZA-27.5-FKS (FTS). 
analysis of changes in monitored parameters, integrated into the main operation algorithm (Figure 8).

Thus, the proposed automated systems (indicated by blue, green and red lines) will be responsible for online visualization, processing (auxiliary microcontroller) and storage of oscillograms of current and voltage flowing in the contact network (the first part of the initial information for the formation of the initial database of the neural network); software tools "GUID" and "KORTES"-participate in the formation of the initial database of the neural network (as the second component). The neural network develops a base of unified setting templates corresponding to each specific individual current train situation in normal operating modes of the traction power supply system, which will be stored on the PC of the traction substation duty personnel. An additional branch with prediction elements (integrated into the body of the main algorithm) programmed into the microcontroller of the relay protection terminal (light green line) can be enabled/disabled by a software key, and if enabled (via an auxiliary microprocessor and a digital visualization channel), triggering/non-triggering of the upgraded the algorithm will be confirmed by the corresponding color signaling displayed on the PC of the personnel on duty.

The automated systems proposed by the authors will perform a purely "tracking" function, as well as collect, process and store information, which will subsequently form the basis for studying the reasons for MRP shutdowns for unknown reasons in order to reduce their number. The normal operation of the terminal will not be disturbed in any way.

\section{Conclusions}

For the first time, the authors obtained the possibility of creating a base of unified templates that include a symbiosis of data about each unique train situation (train weight, type of electric locomotive, speed, train movement mode, coordinate of the point of the outage that occurred, electrical parameters of the contact network, etc.), implemented on the use of self-learning neural network technologies in relation to the dynamics of the train schedule (GUID "Ural-VNIIZhT").

The changes proposed to the standard operation algorithm of the MRP TsZA27.5-FKS (FTS) will make it possible to isolate from the total number of emergency shutdowns of the MRP those that are clearly attributable to unidentified reasons. Subsequently, on the basis of the analysis and the proposed predictive methods, it will be possible to tune out the combination of parameters that lead to the MRP to such shutdowns.

It should be especially noted that the operation of all proposed systems will not affect the normal operation of the MRZ terminal in any way, and the relationship between the PC of the duty personnel and the TsZA-27.5-FKS (FCS) microcontroller will be carried out through an auxiliary microcontroller. Thus, all the information received will be broadcast, processed and stored on this PC and will not interfere with the normal interaction of the operator with the MRP 
terminal during its operation and maintenance [3].

\section{Confirmation}

The study was carried out with the financial support of the Zabaikalsk Rail Transport Institute, a branch of Irkutsk State Transport University (ZABIZhT IrGUPS):

- Grant No. 76-gr of February 24, 2020 "Creation and research of a useful model of a trained microprocessor device for distance protection of overhead line feeders";

- Grant No. 109-gr dated 04/28/2021 "Creation and research of a useful model of an automated microprocessor device for distance protection of overhead line feeders with learning elements".

\section{Conflicts of Interest}

The authors declare no conflicts of interest regarding the publication of this paper.

\section{References}

[1] (2020) Instructions for the Operational Maintenance of Relay Protection and Automation Devices AZm at ZabZhD. ZabNTE, Chita, 12 p. (In Russian)

[2] (n.d.) Operation Manual AB036-00-000-00RE. Digital Protection and Automation Device for a $2 \times 25 \mathrm{kV}$ Traction Network Feeder TsZA-27.5-FTS. 61 p. (In Russian)

[3] (n.d.) Operation Manual AB093-00-000-00_01 OM. Intelligent Connection Terminal $27.5 \mathrm{kV}$ Inter-27.5-FKS. 83 p. (In Russian)

[4] Muraveiko, L.A., Vostrikov, M.V. and Tikhomirov, V.A. (2021) Method of On-Line Visualization and Storage of Information about Currents Flowing in the Contact Network with Reference to the Train Schedule Using the Example of Relay Protection TsZA-27.5-FTS. Young Science of Siberia, 1, 244-249. (In Russian)

[5] Sizykh, V., Daneev, A., Vostrikov, M. and Menaker, K. (2021) The Automated System of Unified Templates as an Element of Trainability of Microprocessor Relay Protection Devices. Journal of Applied Mathematics and Physics, 9, 3045-3057. https://doi.org/10.4236/jamp.2021.912197

[6] (2018) A Program Complex for Calculating Traction Power Supply Systems. General User Manual, Control Software Module of the "KtMain" Complex, JSC "VNIIZhT", Moscow, 60 p. (In Russian)

[7] Radzhibaev, D.O. and Kakhramonov, Sh.N.u. (2021) Analysis of Traction Performance of the "Ermak" Electric Locomotive (3ES5k).Young Scientist, 8, 16-19. (In Russian)

[8] (2021) Regime Maps of the Throughput Capacity of the Sections of the Trans-Baikal Railway. ZabNTE, Chita, 16 p. (In Russian)

[9] GUIDE “Ural-VNIIZHT” [GUIDE URAL-VNIIZHT: Help System] (gidural.ru). http://gidural.ru/doku.php

[10] Kuzmin, O.V. and Starkov, B.A. (2016) Fractal Properties of Binary Matrices Constructed Using Pascal's Triangle Arithmetic and Noise-Immune Coding. Modern technologies, System Analysis, Modeling, 4, 138-142. (In Russian)

[11] Veselova, A.S., Gorelik, A.V., Zhuravlev, I.A., Nevarov, P.A., Orlov, A.V., Savchen- 
ko, P.V., Soldatov, D.V. and Taradin, N.A. (2016) Principles of Data Collection and Processing for Calculating the Performance Indicators of Railway Automation and Telemechanics Systems. Deposited Manuscript No. 165-B2016. (In Russian)

[12] Sizykh, V.N., Daneev, A.V., Vostrikov, M.V. and Menaker, K.V. (2021) Automation of Microprocessor Relay Protection Devices Based on the Use of Neural Network Technologies. Izvestia Tula State University, Tula, 324-337. (In Russian)

[13] Vostrikov, M.V., Menaker, K.V. and Pultyakov, A.V. (2021) Forecasting the Dynamics of Starting and Transient Currents in Order to Increase the Selectivity of Microprocessor Relay Protection Devices of Contact Network Feeders. Transport of the Urals, 1, 86-92. (In Russian) https://doi.org/10.20291/1815-9400-2021-1-86-92

[14] Menaker, K.V., Vostrikov, M.V., Yakovlev, D.A. and Yarov, E.V. (2019) The Device for Filtering and Separating the First Harmonic in Microprocessor-Based Relay Protection Devices for Overhead Line Feeders Based on PLL Circuits: No. 2018134810. Patent No. 2708684 C1 Russian Federation, IPC G01R 31/00, Applicant Federal State Budgetary Educational Institution of Higher Education Irkutsk State Transport University (FGBOU VO IrGUPS). 